\title{
An Architecture for the Mind: $O Z$ magazine and the Technologies of the Counterculture
}

\author{
AnnMarie Brennan \\ brea@unimelb.edu.au
}

\section{Author Bio}

AnnMarie Brennan is the Senior Lecturer of Design Theory at the University of Melbourne and an editorial board member of the Journal of Architectural Education. Her current research focuses on $20^{\text {th }}$ and $21^{\text {st }}$ century design with a strong interest in machines, media, and the political economy of design.

\begin{abstract}
This paper revisits the creative work of the Australian magazine $O Z$ and its founding editors Martin Sharp (1942 - 2013) and Richard Neville (1941 - 2016). Established in Sydney on April Fool's Day in 1963 as a satirical magazine, the editors migrated to London in 1967, where the U.K. version of $O Z$ garnered its status as the underground field guide for enlightened hippies. This paper claims that the visual and rhetorical editorial strategy of $O Z$, coupled with the technologies employed in its making, transformed the medium of the magazine to be more than simply a cipher for hippie life. In fact, it became a platform for immersive, multi-media experiences.
\end{abstract}

\section{Keywords}

Architecture, media, OZ magazine, immersive environment, counter-culture, technology, multi-media environment, Marshall McLuhan

In the February 1968 issue of the alternative culture magazine $O Z$, designer Martin Sharp published the fold out graphic poster "If I Could Turn You On ...” an elaborate illustration of a figure's head (Figure 1). At the center of the composition is a window appearing as a threshold to enter through the figure's forehead and into the mind. It frames a view to a colonnade reminiscent of a mosque; a type of architectural feature Sharp encountered during his travels through Asia en route to London accompanied by his co-editor Richard Neville. Layers of space exist between the framed window and the colonnade. The shutters of the window are open, depicting 
images of the sun, clouds, and moon. Inspired by the large trees sprouting from the massive, 10-foot head sculptures Sharp visited during his trip to Angkor Wat, Cambodia, the designer, first fully experiencing the effects of marijuana, created the figure of a giant plant sprouting two eyes - a common element reappearing in his work.

Spiraling from the center of the window, or 'mind' of the figure, is the quote "If I could turn you on; If I could drive you out of your wretched mind; If I could tell you I would let you know" repeated three times. This quote, taken from the 1967 book The Politics of Experience and the Bird of Paradise by the controversial Scottish psychologist R. D. Laing, invoked the teachings of this pioneer in LSD experimentation within psychiatry (Laing 1967, 190). In this text, Laing challenges the idea of normalcy in a modern world and claims that people should not be diagnosed as being mad since it was modern society that was insane.

Posters like this one, created by Sharp and other psychedelic artists, served a very particular purpose for a distinctive type of experience. ${ }^{1}$ They were not advertising a product or an event like a concert or light show; they were intended for interior, domestic spaces. The posters, with their playful, bright colors and complex, rendered surfaces served as instruments intended to assist $O Z$ readers in creating what LSD advocate Timothy Leary described as "set and setting."

Robin Middleton, editor of the British periodical Architectural Design (AD) during the late 1960s, would later recall of this moment a kind of "graphic convergence" of underground counterculture with architecture journals (Colomina and Buckley et. al. 2010, 422). For some time, architects, designers, and editors considered 
$O Z$ 's influence merely as a hallmark of style. But the visual art of Sharp and the sociopolitical proclamations of Neville provided a powerful means of counter-cultural expression channeled through the vibrant, printed surfaces of the transformative medium of the underground magazine. Unlike previous magazines, $O Z$ expanded the notion of what a publication could be by including supplementary artifacts embedded within the magazine that aimed to create environments conducive to experiencing the psychedelic effects of hash and LSD. Designed as part of the publication, the artifacts comprised of game boards, stickers, and posters like "If I Could Turn You On ...". These psychedelic tools, reinforced by the content of the magazine, expanded the potential of print media and contributed to creating an alternative, sensory-driven atmosphere that complemented the use of hallucinogenic drugs, rock music, and light shows.

Moreover, in their attempt to counter the conservative, hegemonic culture of the 1960s in Australia and the U.K., the editors of $O Z$ harnessed and exploited the technologies implemented in its making. The magazine became a pioneering force in challenging cultural norms by reporting on and parodying issues in Australia such as the legality of abortion in New South Wales, police brutality, the White Australia Policy, and censorship. Later, in the U.K., $O Z$ featured special themed issues on the topics of feminism, homosexuality, inter-racial relationships, and the anti-Vietnam war movement. By examining the development of $O Z$ magazine, this paper unearths the key strategies employed by Neville, Sharp, and others and suggests that this editorial scheme, based on a new set of cultural values and technical inventions, led to an 
original approach toward fulfilling the desire of counterculture participants for spatial, multi-sensorial immersive experiences.

\section{Pee \& Owe: 'Misreading' Architecture}

While usually remembered as a magazine which helped establish the counterculture and serve as a guide to hippie life in the swinging London of the late 1960s, $O Z$ originated in Sydney as a publication satirizing conservative Australian and British politics and culture. Its founding editors, Neville, Sharp, and Richard Walsh, were young Australians who shared an interest in starting a magazine. The project had a successful beginning, with the inaugural issue selling 6,000 copies on the first day of its launch (Neville 1995). However, this success would be short-lived as the first three issues featured controversial topics such as abortion, homosexuality, police brutality, and the Vietnam War that in turn garnered the attention of the police. The three editors at the time, Neville, Walsh, and Peter Grose, were summoned on charges of distributing a publication deemed obscene. While the editors believed they were innocent, the editors pled guilty following ill advice from their lawyers. Despite this setback, the publication continued, with Martin Sharp replacing Grose. However the editors soon encountered a second round of charges for subsequent issues. One controversial issue arose on February 6, 1964, when the editors not only critiqued corporate modernist art and architecture, but playfully employed verbal and visual punditry to parody Establishment values within the urban setting of Sydney (Figure 2).

The magazine cover featured an image of Neville and two other young men standing in front of a Tom Bass fountain sculpture installed at the base of the $\mathrm{P} \& \mathrm{O}$ 
Shipping Line Building. A month earlier, the right-wing Prime Minister Robert Menzies officially opened the recently completed building to much fanfare before an audience of businessmen. The three young men in the magazine cover photo appear to be literally 'taking a piss' into the recessed wall fountain located along the sidewalk in the heart of Sydney's business district. This somewhat shocking image is accompanied by the caption:

On the corner of Hunter and Castlereagh Streets, Sydney, the P \& O Shipping Line has completed its contribution to the Australian Ugliness....To alleviate the severe drabness of its sandstone façade, sculptor Tom Bass had set an attractive bronze urinal in the wall for the convenience of passers-by. This is no ordinary urinal. It has a continual flushing system and basins handily set at different heights. There is a nominal charge, of course, but don't worry, there is no need to pay immediately. Just $\mathrm{P} \& \mathrm{O}$.

This humorous cover photo and caption, along with other infringements against the Australian norm of decency landed the editors in court on obscenity charges. Much attention has been given in Australia and the U.K. to the obscenity trials that challenged the boundaries of decency and free speech. Less studied, however, is the particular manner in which $O Z$ redefined the possibilities of a magazine to successfully counter the absurdity of Australian and British conservative culture and visually define the ethos of the counterculture movement utilizing technological advancements.

The first line of the cover photo caption refers to the canonical treatise, The Australian Ugliness, by Australian architect Robin Boyd. Published in 1960, the bestselling book criticizes what Boyd defines as "Featurism"- -the comforting "beautification" of the kitsch, aesthetically-numb, and ugly approach of Australian suburban development during the 1950s and 60s. Featurism entailed three fundamental criticisms found in the emerging Australian suburb: the elimination of trees to ease 
maintenance, the designation of building materials that did not suit the Australian landscape and climate, and the penchant for Australian buildings to focus on individual parts of a building rather than designing it as a whole work. Sharp, who attended the first year of the Architecture program at Sydney University in 1961 through the urging of his father, would have known the text. The high Modernist P \& O building did not exemplify the concept of Featurism. But in a reversal of terms, the editors used this now familiar phrase of 'Australian Ugliness' to criticize the very modernist architectural style that Boyd championed to counter Featurism, as it represented the conservative values of the economic and political establishment.

At work in the $O Z 6$ Sydney cover are two types of puns created through the use of pre-existing forms that are given new meaning according to their connection to other forms. The visual pun is created by the re-appropriation of the familiar-here, a fountain that is replaced with an alternative use as a very public urinal. This pun is made by taking what is usually a very banal but semi-private scene - men peeing before a urinal - and transforming it into a public display by placing the activity along the streets of Sydney. Also employed here is the verbal pun of $\mathrm{P} \& \mathrm{O}$. This is the name of the owners of the building, the Pacific \& Orient Shipping Company, shortened to simply P \& O. However in this instance language is manipulated to contain the more scatological meaning of 'pee and owe,' which is further reinforced by the cover image.

For these editors to make both visual and rhetorical jokes, they were first required to envision the urban scene as a text. Derived from French continental theorists such as Roland Barthes and Mythologies, his 1957 book on semiology, this way of 'reading' the built environment as a text in which to derive meaning was an 
insightful method to make connections between seemingly banal events to larger narratives while depicting apparently serious topics as humorous. ${ }^{2}$ Instead of viewing the building and fountain solely in terms of the Modernist ethos of form and function advocated by Boyd and other modern architects, the editors 'read' —or rather purposefully 'mis-read'—Boyd's text on Australian architecture and the Sydney urban scene. They intentionally misappropriated the function of the fountain for that of a urinal. The $O Z$ editors' joke of re-appropriating the Bass fountain as a urinal was an ironic reversal of Marcel Duchamp's strategy of claiming that his 'fountain' of 1917, a porcelain urinal, was, in fact, a work of art created by placing it on a pedestal in a museum.

In addition to the cover of $O Z$ 6, a cartoon by Sharp illustrating a long-haired folk singer playing the guitar with the controversial title "Get Folked," shocked the courtroom at the obscenity trial, and the editors were ultimately forced to plead guilty as advised by their lawyers. The magazine, now a primary target of the New South Wales Vice-Squad for Obscenity after the trial, turned their editorial focus from merely satirizing Australian politics to challenging the conservative government censorship. Driven by their new cause, future cartoons, columns, and articles took aim at the strict censorship laws imposed by the conservative Liberal government. Such columns included "This Month in Censorship" and "Banned Any Books Lately?"

\section{OZ London: the Downundergrounders and the Form of Dissent}

OZ Sydney continued publishing until 1970 under the editorship of Walsh. However in 1966 Neville and Sharp left Australia and set out to explore London via the 'pot trail' 
through Cambodia, Thailand, and Nepal. Once in London and reunited with his girlfriend and $O Z$ collaborator author Louise Ferrier, ${ }^{3}$ Neville reinvented the magazine as an underground publication. As such, it became a major participant in the most powerful force of the counterculture, the Underground Press Syndicate. More than just a means of dissent, the Underground Press formed a network of interconnected journals that might even be considered a precursor to the Internet. The Syndicate was based on the premise that it allowed its members to reprint the content from other Underground publications, to freely exchange subscriptions, and to publish a list of all other Underground newspapers and their respective addresses. In this way, cartoons, columns, and news stories contributed to the Syndicate became widely distributed internationally within counterculture channels.

In the move from Sydney to London, the editorial approach of $O Z$ evolved over time and according to location. ${ }^{4}$ The initial $O Z$ Sydney was known for attacking their subjects through parody and a cheeky, somewhat silly high-school humor. Conversely, OZ London became well-embedded within the politics and approaches of the Underground Press, challenging the established norms and attempting to shock with a content and an aesthetic based upon the newfound values of liberated sexuality, experimentation with drugs, and the encompassing influences of a technologicallyinspired psychedelic 'space' or 'acid' rock music. As Neville depicts in his 1968 manifesto Play Power, OZ aligned its editorial line with that of the youth counterculture movement, which focused on similarities that transcended traditional borders of nationality and language and provided this burgeoning faction with a platform to "share solidarity and common aspirations, style, mood, and vocabulary." Describing 
the priorities of this group, Neville proclaimed: "Long hair is their declaration, pop music their Esperanto, and they puff in [sic] their peace pipe." $($ Neville 1968, 10) What is not recognized by Neville at this time are the advanced technological methods applied to achieve these seemingly clichéd goals of the counterculture.

OZ London quickly earned its reputation through the distinctive and psychedelic form rather than the content of its articles. The accomplished graphic designer Pearce Marchbank, working as Art Director at the British periodical Architectural Design $(A D)$ notes, the design and form of $O Z$ distinguished itself from other London Underground publication competitors such as International Times (IT) through its highly original design. He writes that "when [issue 2 of] $O Z$ came out, which was printed in litho and designed by Martin Sharp on white cartridge paper with beautiful thick black ink and bright red ink and a huge pair of lips on the front, it was like the sun had come out." (Green 1988, 152). Neville recruited a higher caliber of writer for feature articles than most Underground publications. Contributors included noted Australian expats from the Sydney Push such as feminist author Germaine Greer, novelist Clive James, and the art critic Robert Hughes. But it was Sharp's graphic style that set the magazine apart from others. Comparing $O Z$ to other Underground publications, Marchbank said, "It was like the first time you hear stereo as opposed to AM radio. You could see the possibilities of print. $I T$ was content, whereas $O Z$ was form.” (Green 1988, 152)

Along with the feature articles garnered by Neville, the magazine included the syndicated columns of Dr. Hip-ocrates, a Q \& A column on sex, and the fortnightly newsletter 'Other Scenes' by Underground Press Syndicate co-founder John Wilcock. 
With every issue, the editors attempted to redefine the boundaries of what a magazine could be and how it could provide its readers with the requisite information and accouterment of hippie counterculture, while at the same time attempting to create a total sensory environment of cool visuals in which to get your groove on.

The ideology that drove such novel inventions was premised upon Neville's prioritization of fun and play. For example, issue 2 featured a poster/calendar with a cartoon called the Toad of White Hall, satirizing British Prime Minister Harold Wilson. Issue 3 contained political protest postcards, and issue 4 incorporated a double-sided gold quadruple cover/poster of Tantric lovers by Underground graphic designer Michael English of the graphic duo Hapdash and the Coloured Coat accompanied by an insert of punch-out tarot cards designed by Sharp and Jim Leon. ${ }^{5}$ Issue 11 included a set of stickers by Sharp and invited readers to decorate the issue's red cover illustrated with scribbly cartoons and sketches. It was even rumored that issue 3 contained a page with acid dropped onto one of its corners, and, if ingested, could be enjoyed by its readers. $O Z 12$ featured two doubled-sided, fold-out posters designed by Barney Bubbles (aka Colin Fulcher) and his design partner David Wills (credited as Eric Stodge). The posters are a collection of cartoons and game boards which appear as modern, collaged mandalas. Composed by physically gluing and overlapping images cut from 1950s books on the history of cinema and the history of technology with Kodatrace and primary colors, the posters even include hash-based recipes for Brownies Cockaigne and Gingerbread tea cake.

\section{Magic Theatre: Price of admittance, your mind ...}


In his second retrospective book chronicling his adventures during 1960s London, Hippie, Hippie, Shake, Neville describes how Sharp, high on hash, announced that he would create an entire issue of $O Z$ by himself (Neville 1995). OZ 16, named the 'Magic Theatre' issue, refers to a metaphorical place in Herman Hesse's 1924 novel Steppenwolf, wherein the protagonist, after ingesting a special 'potion,' transforms into a wolf and encounters a 'magic theatre' that allows him to relive, observe, and edit moments from his past, exploring the latent fears and desires of his unconscious mind (Figure 3). Sharp incorporates into the cover illustration a line from Hesse's novel: "Anarchist Evening at the Magic Theatre, For Madmen Only, Price of Admission Your Mind." The composition is designed as a theater stage and features large swaths of red curtains framing both the front and back cover. In the foreground, and present throughout the issue, are cartoon versions of Eadweard Muybridge's running figures, which interject a type of Dadaist narrative in the form of comic strip dialogue bubbles. In the center of the cover composition are two men boxing, again taken from a still from the motion study photography. Like a recurring dream, they frame the reappearance of the gigantic plant containing eyes and Sharp's characterization of Neville featuring his iconic smiley mouth with large red lips (Figure 4).

Consisting of 48 pages of collage work, the magazine issue featured a vast array of characters ranging from John Lennon and Yoko Ono to Richard Nixon, Buddha, and Adolf Hitler. Images were sourced from newspaper clippings, comic strips, Victorian catalogs and Surrealist paintings. Neville described the pages as "textured with multi levels of meaning" derived through a process of associative juxtaposition (Neville, 1995, 43). 
These same collage techniques are evidenced in Max the Birdman Ernst, a 1967 poster by Sharp, a lithograph that re-works a print by Max Ernst (Figure 5). Ernst's work was part of a 1934 collage novel titled Une Semaine de Bonte (A Week of Kindness). This wordless novel, comprised of seven parts with 182 images, depicted seven days of the week using collages of Victorian-era illustrations cut from encyclopedias, magazines, and other novels.

Apparently inspired by Ernst, Sharp's depiction uses the same exact print by the artist but adds another layer of meaning onto the original Birdman collage by incorporating a title at the bottom of the print and coloring the beak, the eye of the Birdman, the egg, and the female figure in hot pink. This image is then silk screened onto reflective, metallic cardstock. Similar to Ernst, Sharp's creative works drew from the Freudian idea of the unconscious--in Sharp's case, a drug-enhanced unconsciousness--serving not only as the subject of the work but as a means to structure it.

Art critic and historian Robert Hughes christened the Magic Theatre issue the "greatest achievement of the entire British Underground Press." But the issue received much criticism from its readers. Hughes defended Sharp's work in a full-page letter to the editor appearing in the following issue. He began his retort by pointing out that Sharp's detractors claimed to be avant-garde but were quick to criticize "a mode of presenting images which has been central to modern art since John Hartfield and Max Ernst. Only its application to a magazine, in the extended form, that Sharp has given it, is new." (Hughes 1968, 12) Hughes noted the irony that the critics who echoed comments made by Marshall McLuhan regarding the "instantaneous communication 
across the global village" and the "death of the written word" were the same people who wrote hostile letters criticizing Sharp's attempt to use the medium of the magazine to create a novel work of art, "If you have difficulty with Sharp's narrative collage what problems will you not have with Paolozzi's 'Moon Strips Empire News?' I suspect that the complainers are the sort of people who will parrot the belief that a wired up discotheque is an information-processing center while thinking that a college is not." (Hughes 1968, 12) Hughes concluded his letter by citing Sharp's issue as “one of the richest banks of images that has ever appeared in a magazine" (Hughes 1968, 12).

Hughes' mention of the global village and the death of writing was a specific reference to the1967 text, The Medium is the Massage: An Inventory of Effects, where McLuhan proclaimed that, as an extension of the human senses, media expands or 'extends' the abilities of the nervous system by massaging the aural and tactile capacities of the human sensorium. Though McLuhan had by this time proclaimed that print media was dead and was proselytizing the potential 'cool' of electronic media like television that allowed for participatory, multi-sensory experiences, McLuhan and Quentin Fiore participated in editing and designing an issue of another magazine which contradicted this message.

In 1967 (a year before the Magic Theatre $O Z$ issue) McLuhan published a version of his The Medium is the Massage in a box issue of the avant-garde multimedia magazine Aspen. ${ }^{6}$ This magazine of the arts, published by Phyllis Johnson, was promoted as a "three-dimensional magazine" with an editorial line promoting "culture along with play." Each magazine, featuring a different editor and designer, was in the 
form of a box that contained a plethora of various media such as booklets, records, posters, postcards and even Super 8 film. Attempting to reflect the counterculture mood of the time, McLuhan's issue no. 4 contained: a poster version of The Medium is the Massage, a diary by John Cage, a flexi-disc of electronic music, and articles on San Francisco's psychedelic scene in Haight-Ashbury and the geodesic-domed community in Drop City, Colorado.

Working on this multi-sensory issue of Aspen, McLuhan fulfilled his prophecy that print media, once rendered obsolete by newer 'cool' technologies, would unleash its optimal potential as an artistic medium. McLuhan's thought on the transformation of old (print) media was asserted by Aspen founder Johnson when she described how a subscriber would experience the magazine, "you don't just read it: you hear it, hang it, feel it, fly it, sniff it, taste it, fold it, wear it, even project it on your living room wall." (Proctor 2013) Despite its traditional limit of two-dimensional pages of images and printed text, the founders of $O z$ and Aspen magazine attempted to surpass the limitations of those dimensions by orchestrating publications that functioned as environments fostering an immersive experience of counter-cultural activities affecting all of the human senses.

Hughes mentions that the form of the magazine was perhaps a flawed medium for Sharp's Magic Theatre issue. However, a closer look at the manner in which $O Z$ was produced reveals an interesting explanation for this choice. The counter-culture, according to Neville in his treatise Play Power (1970), came about as a result of new technologies. In turn, these new technologies assisted people in envisioning a new total environment filled with novel experiences. He writes, 
Counter-culture is a brainchild of the new technology. Light shows require sophisticated electronic equipment, from adjustable stroboscopes to multiinjector projectors finely synchronized with the rhythms of rock and roll. And just as rock depends on a group, so products of the new culture are symbiotic; they work better all together. The most memorable experiences underground are when you connect to the music, to the light show, happening and movie simultaneously, while being stoned and fucking at the same time - swathed in stereo headphones, of course. (Neville 1970, 63)

Neville's assertion that significant shifts of culture coalesced through the introduction of new technological methods is furthered by media theorists Friedrich Kittler and Vilem Flusser, who recognized that cultural transformations are technical rather than ideological. As Flusser claimed, "really effective revolutions have always been technical.” (Flusser, 2011, 62)

These new technologies give priority to, as Neville's above quote demonstrates, the actions of collage and assemblage, depicting a configuration of overlapping, simultaneous events, sensations, and visuals. New advances in printing technology, in the form of offset lithography (aka photo-offset printing), fostered a new way of assembling the magazine through the simplified process of cutting, pasting, and photographing.

As a planographic printing method, offset lithography does not rely on an imprint of three-dimensional metal letterforms for the adhesion of ink. Instead, it consists of both image and non-image areas equally becoming part of the twodimensional plane of the printing plate. The offset litho photographic process uses paper or film as a medium substrate upon which images and texts are composed. Additional options of illustrating images such as halftones and line art come into play through the use of photomechanics, which entails the use of a camera to take a 
photographic image of the pasted up composition of image and text. The negative film of the photographic image would then be transferred to a printing plate through a process not unlike the development of film. However, the offset litho process has rightreading plates, meaning that when the composition undergoes the photomechanical process, it is not 'backwards' as in traditional letterpress. As a result, it is easier to detect errors and correct them (Daly et al. 1997).

Photo-lithography, with its cut-and-paste process, was a technology that enabled the Underground Press Syndicate to exist. It can be understood as a type of collaged text of interchangeable columns, articles, and images exchanged within an international network. Beginning with Sydney OZ 12 of August 1964, the editors began to use offset lithography. Neville claimed that " $O Z$ going offset" was like "Dylan going electric" since it afforded Sharp and the rest of the editorial staff greater creative freedom in composing text with images, as well as greater speed in the pasteup process (Neville, 1995, 43). The act of assembling an issue afforded by the new technology of offset lithography was not unlike the assemblage of a collage; it was inevitable that this new process would have an effect on both the visual aspect and content of the magazine.

\section{Set and Setting: Magazine as Hallucinogenic Helper}

In his book The Psychedelic Experience, Timothy Leary notes that the mindset and the setting of a person experiencing LSD were important factors contributing to the comprehension of the new realities of inner space and "expanded consciousness." He writes, that "the drug dose does not produce the transcendent experience. It merely acts 
as a chemical key - it opens the mind, frees the nervous system of its ordinary patterns and structures. The nature of the experience depends almost entirely on set and setting." While 'set' described taking an inventory of one's individual emotions and mood, 'setting' denoted the physical environment and included such factors as "the weather, the room's atmosphere" (Leary 1964, 1).

LSD users reportedly experience a higher state of consciousness, and their sensations become expanded and amplified. The attraction of LSD is that it inhibits the functioning of neural mechanisms which hinder sensory input, and in turn allow for a flood of sensory experiences to occur all at once, forming a state of synesthesia. Sounds have color, and colors are brighter and glow with scents and tastes. Both Neville and Sharp were familiar with LSD, as Neville wrote about how he unwittingly had ingested the drug by drinking some tea offered to him by Sharp at his London apartment (Neville 1995). Sharp even designed the cover of another book by Leary, The Politics of Ecstasy. The OZ posters, supplemented with hallucinogens, were intricately rendered surfaces of the magazine page designed to perform as vehicles of self-discovery--a visual refuge in the case of a bad trip, and as potential windows to an alternative, interior space of the sub-conscious mind. ${ }^{7}$

Hallucinogenic drugs played a key role in the music of psychedelic space rock musicians such as Jimi Hendrix, Pink Floyd, and Cream. For these musicians, and for some members of the counterculture, LSD was more than simply about getting high; it was a means to raise consciousness and experience the mystical and religious symbolism engendered by the effects of this powerful drug. Sharp's tribute poster for Bob Dylan, entitled 'Mister Tambourine Man,' first appeared on the cover of $O Z 7$ in 
the autumn 1967 before it was produced as a poster (Figure 6). This iconic rendering of Dylan by Sharp has the song title and the modified lyrics of "Blowing in the Mind" in the lens of Dylan's sunglasses written in Sharp's characteristic font reminiscent of a schoolboy's doodling in his notebook. The image, printed on metal-coated paper, added another psychedelic effect by allowing the viewer to see his/her reflection montaged onto the mirror-like surface of the poster.

A celebration of rock and the LSD experience can be seen in Sharp's portrait of Jimi Hendrix, which was a poster included in $O Z$, issue 15, October 1968 (Figure 7). With this image Sharp not only represented the dissenting, rebellious countercultural era. His poster signaled an emerging cultural change which arose from a desire to produce new sensorial experiences of pure sound surrounding the listener. Germaine Greer claimed in a recent article that "if you want[ed] to know what the 60s were like, then look at Martin Sharp's work" (Greer 2009). As Greer recalls of the Hendrix poster,

I have a memory... of going into the studio [Sharp] shared with Eric Clapton, and seeing a full-length study of Jimi Hendrix that he was painting in vibrant acrylics, on the back of several layers of Perspex film. That image of Jimi holding the Fender in his left hand, with his right holding the pick flung out parallel to the guitar neck, while a multi-coloured explosion begins at the strings and streams to the four edges of the picture, is an ikon [sic] of 1967. (Greer 2009)

Both the subject and form of Sharp's Hendrix poster encompassed many of the new approaches to collaged experiences that exploited the potential of new technologies. Rock critic Richard Meltzer explains Hendrix replaced the usual "tunnel space" of traditional rock with his version of "paisley space - a wormholey, fractal surround sound with Jimi coming at you from all sides, from behind you, sometimes 
seemingly from inside you." (Meltzer 1967) Hendrix created these "soundscapes" by pushing technology to its limits with the help of his sound engineer Roger Mayer, a former sonic wave engineer for the British Ministry of Defense who invented many of the electrical devices and spatialized sound equipment used by Hendrix such as wahwah pedals and the Octavio, producing a "doubling" echo resulting in a 3D effect.

The Hendrix poster exemplified the practices of the Underground Press Syndicate by borrowing (without attribution required) and tracing the photograph of Hendrix taken by Linda Eastman (soon to be Linda McCartney), and manipulating it through a painterly technique that translated Hendrix's explosion of sound into brightly-colored splattered paint. Like Hendrix who became known as a "rock artist" obsessed with studio technique of overlapping sounds and effects, Sharp's poster was a technical image of layered images and colors.

\section{Conclusion}

OZ magazine would come to an end in 1973, publishing over 48 London editions between 1967 and 1973. Its finale would be precipitated by what became, in 1970, a third set of charges in the longest obscenity trail in British legal history. ${ }^{8}$ With the May 28, 1970 issue of $O Z$, the editors at the time, Neville, Jim Anderson, and Felix Dennis, in response to claims that the magazine was out-of-touch with young people, recruited school kids to curate the issue. The controversy arose when $O Z$ published an $\mathrm{X}$-rated Robert Crumb cartoon strip collaged with the head of the childhood figure of Rupert Bear created by school kid guest editors. Initially Neville, Anderson and Dennis were found not guilty on the charge of conspiracy to corrupt public morals, but they were 
ultimately convicted and sentenced to imprisonment on obscenity charges. However on appeal, it was discovered that the judge misdirected the jury, and the convictions were eventually overturned.

Luckily for Sharp, he left London and returned to Australia before the issue was published, thus avoiding the trial. During his time in London, Sharp would become homesick for the beaches and sun of Sydney (Tarling, 2016). At one point he decided to visit an Australian friend staying in the Balearic Isles off the coast of Spain. It was the location where Sharp believed the Sirens apparently sang to Ulysses, and this journey became the inspiration for the lyrics of "The Tale of Brave Ulysses," a song he would eventually pass on to his roommate and friend back in London, Eric Clapton, from the rock band Cream. ${ }^{9}$ Part Greek mythology, part autobiography, Sharp's lyrics called upon the love of the gods to illustrate the LSD-inspired, neurological phenomenon of synesthesia; whether it was the "blinding of eyes from the color of the sea," the touch of the "distant beaches," the "Sirens singing sweetly," or the "Carving deep blue ripples in the tissue of your mind." Sharp recalls the immersive and beguiling sound of the Sirens; a sound that would ultimately be translated into the electronic sound of Clapton's guitar.

$O Z$ magazine and the technical apparatus used to create the multi-media experiences exemplify McLuhan's dictum that media, like tools, work on us just as much as we work on them. By this he meant that media is ontological and epistemological, intellectually forming those subjects who participated in the counterculture movement. Between the music, a magic theater, and the mind, the case 
of $O Z$ magazine illustrates that the fate of knowledge and innovation is born from play, love, and the technologies of media.

\section{Acknowledgments}

Many thanks to Michael Organ at the library of the University of Wollongong, Australia. The University hosts a digital database of the entire collection of $O Z$ magazines issues from both Sydney and London. An early version of this paper was presented at the $30^{\text {th }}$ Annual meeting of the Society of Architectural Historians, Australia and New Zealand at Griffith University, Gold Coast, Australia, 2013.

\section{References}

Baumeister, Roy F. 1984. "Acid Rock: A Critical Reappraisal and Psychological Commentary," Journal of Psychoactive Drugs 16 (4) Oct-Dec: 339-344.

Colomina, Beatriz and Craig Buckley, et al. 2010. Clip, Stamp, Fold: The Radical Architecture of Little Magazines 196X - 197X. Barcelona: Actar.

Daly, Charles P., Patrick Henry, and Ellen Ryder, 1997. The Magazine Publishing Industry. Boston: Allyn and Bacon.

Flusser, Vilem. 2011. Into the Universe of Technical Images. Nancy Ann Roth, trans. Minneapolis: University of Minnesota Press.

Fountain, Nigel. 1988. Underground: the London Alternative Press 1966-1974. London: Routledge.

Freud, Sigmund. [1905], 1960. Jokes and their Relation to the Unconscious. London: Penguin Books.

Green, Jonathon. 1988. Days In the Life. London: Heinemann.

Greer, Germaine 2009. "Want to Know What the 60s Were Like? Then Look at Martin Sharp's Work?” The Guardian. November 22, accessed January 21, 2013. http://www.guardian.co.uk/artanddesign/2009/nov/22/germaine-greer-martin-sharp. 
Guffey, Elizabeth E. 2015. Posters. London: Reaktion Books.

Hein, Ethan. 2009. "Jimi Hendrix, electronic musician.” The Ethan Hein Blog. July 6, accessed October 17, 2016. http://www.ethanhein.com/wp/2009/jimi-hendrixelectronic-musician/.

Hughes, Robert. 1968. "Letter to the editor," $O z$ 17, December: n.p.

Kittler, Friedrich. 1999. Gramophone, Film, Typewriter. Stanford, CA: Stanford University Press.

Laing, Ronald D. 1967. The Politics of Experience and the Bird of Paradise. London: Penguin.

Leary, Timothy, Ralph Metzner, and Richard Alpert. 1964. The Psychedelic Experience: A Manual Based on the Tibetian Book of the Dead. London: Academic Press.

McLuhan, Marshall. and Quentin Fiore. 1967. The Medium is the Massage. London: Penguin Books.

Meltzer, Richard. 1967. "Jimi Hendrix \& Pythagoras the Cave Painter," Crawdaddy 11, Sept/Oct. Accessed August 14,, 2017. https://www.pastemagazine.com/articles/2015/06/crawdaddy-classics-pythagoras-thecave-painterjimi.html

Morgan, Joyce. 2017. Martin Sharp. His Life and Times. Crows Nest: Allen \& Unwin.

Neville, Richard. 1970. Play Power. Exploring the International Underground. London: Cape.

- 1995. Hippie, Hippie, Shake. The dreams, the trips, the trials, the love-ins, the screw-ups, the Sixties. Melbourne: William Heinemann.

Proctor, Jacob. 2013. “Avant-Garde Aspen,” Aspen Sojourner, Midwinter/Spring. Accessed March 20, 2014. https://www.aspensojo.com/articles/2013/2/1/avant-gardeaspen

Reynolds, Simon. 2000. "Jimi Hendrix Reconsidered," Uncut, July. Accessed October 17, 2016. http://reynoldsretro.blogspot.com.au/2013/02/jimi-hendrix-reconsideredessay.html

Tarling, Lowell. 2016. Sharp 1942-1979. A Biography of Martin Sharp as Told to Lowell Tarling, Sydney: ETT Imprint. 
Vulliamy, Ed. 2010. "Jimi Hendrix: 'You never told me he was that good," The Guardian. August 8. Accessed October 17, 2016.

https://www.theguardian.com/music/2010/aug/08/jimi-hendrix-40th-anniversary-death.

\section{Image Captions}

Figure 1: "If I Could Turn You On...." Graphic from OZ 9, Feb. 1968 by Martin

Sharp.

Figure 2: Cover of $O Z$ magazine Sydney featuring fountain sculpture by Tom Bass, issue no. 6, February 1964.

Figure 3: Front and back cover of Magic Theatre issue of $O Z$ 16, Nov. 1968 by Martin Sharp.

Figure 4: Double page spread from Martin Sharp's Magic Theatre issue of $O Z$ 16, Nov. 1968.

Figure 5: Max the Birdman Ernst by Martin Sharp, 1967.

Figure 6: Poster of Bob Dylan, "Mr. Tamborine Man,” OZ 7, 1967.

Figure 7: Poster of Jimi Hendrix by Martin Sharp. From $O Z$ issue 15, Oct. 1968.

\footnotetext{
${ }^{1}$ For more on the purpose of the psychedelic poster during this time, especially in the San Francisco Bay Area, see Elizabeth Guffey, Posters, (London: Reaktion Books, 2015), $152-169$.

${ }^{2}$ For a recent and insightful review of Barthes' Mythologies, see D. J. Huppatz (21) "Roland Barthes, Mythologies," Design and Culture, 3:1, 85-100.

${ }^{3}$ Louise Ferrier is on the cover of $O Z$ magazine issues no. 8, 17 with fellow Australian expat and textile designer Jenny Kee.

${ }^{4}$ Digitized versions of all $O Z$ Sydney and London issues can be found at http://ro.uow.edu.au/ozlondon/.

${ }^{5} \mathrm{An}$ image of this fold-out poster can be found in the V \& A collection. http://collections.vam.ac.uk/item/O1155465/itantric-loversi-oz-cover-poster-englishmichael/

${ }^{6}$ Digitized version of items from the Aspen magazine can be found at http://www.ubu.com/aspen/.
} 
${ }^{7}$ Reprints of the posters included in $O Z$ were later created by The Big O Poster Company, established by a member of the London $O Z$ magazine staff, Peter Ledeboer, who, after witnessing the popularity of $O Z$ magazine issues containing posters, saw an opportunity to expand into the business of simply making posters for the counterculture crowd.

${ }^{8}$ These videos show a brief 2-part documentary providing background for $O Z$ magazine, followed by a re-enacted television drama re-enacting the U.K. obscenity trail. Robertson, Geoffrey and Hugh Grant. The Trials of OZ. Television drama. Sheree Folkson. London: BBC, 1991. http://v.youku.com/v_show/id_XNzcwNzgzODg=.html. Accessed March 20, 2017. See also: Chitra Ramaswany, "Return to Oz: the most controversial magazine of the 60s goes online," The Guardian, March 7, 2016, accessed March 20, 2017, https://www.theguardian.com/media/shortcuts/2016/mar/06/return-oz-mostcontroversial-magazine-60s-goes-online and http://v.youku.com/v show/id XNzcwNzgzODg=.html; Roger Lewis, "Never Mind Lady Chatterley - the censorship trail that changed Britain was a courtroom farce 40 years ago all about sex, drugs and Rupert Bear," The Daily Mail, 12 November 2011, Accessed March 20, 2017, http://www.dailymail.co.uk/news/article-2060612/NeverMind-Lady-Chatterley--censorship-trial-changed-Britain-courtroom-farce-40-yearsago-sex-drugs-Rupert-Bear.html.

${ }^{9}$ In addition to writing the lyrics to this canonical song by the rock band Cream, Sharp would illustrate the band's award-winning LP covers to Disreali Gears (1967) and Wheels of Fire (1968). 